\title{
EL "COGITO" CARTESIANO: ESCISIÓN ÓNTICA DE LA ONTOLOGÍA
}

\author{
Àlex Verdés i Ribas \\ (IES "Olorda", Sant Feliu de Llobregat, Barcelona)
}

\begin{abstract}
Las consideraciones de Canals Vidal sobre el "cogito" cartesiano giran en torno a lo que llamannos "escisión óntica de la ontologia". O sea, la proyección del pensamiento critico sobre "si mismo", interpretado segủn el postulado intuicionista, interfiere la comprensión de la mismidad pensante por su ser espiritual. Esta escisión entre ser y pensamiento se desarolla en una triple tendencia: como "sujeto", cono "idea" y conno "esencia".
\end{abstract}

\section{La escisión del sujeto}

Aparentemente, el "cogito" cartesiano es modelo de una inmediatez intuitiva de orden entitativo que impone la perspectiva dominante de la génesis del idealismo en la "quaestio de ponte". Si recordamos la fase "analitica" de invención del "cogito" expuesta en las Meditaciones metafisicas, esta concluye con la subordinación del pensamiento de si mismo como existente a la voluntad crítica radical de afirmaciones necesarias en el rechazo a lo falso de lo probable mediante la figura del genio maligno: "Haud dubie igitur ego etiam sum, si me fallit; \& fallat quantum potest nunquam tamen efficiet, ut nihil sim quamdiu me aliquid esse cogitabo" (MM II, AT, VII, 25). La afirmación de la existencia de uno mismo seria necesariamente verdadera porque en esto que la pienso en el ejercicio de la voluntad critica radical contra mi mismo, más intensa se hace la presencia de mi existencia. Esta es la dimensión óntica del cogito que considera Canals en Cuestiones de fundamentación: "La mismidad consciente de la res cogitans lleva en si el testimonio indubitable de la presencia e identidad por la que el y'o es consciente de su existir por la transparencia y subsistencia en si del pensar en acto" (Op cit., EU, Barcelona, 1981, p. 120). En el registro critico radical reiterado mediante la figura del genio maligno, el pensamiento es lo único que no puede separarse de mi: "cogitatio est, haec sola a me divelli nequit" (MM II, AT, VIl, 27). Pero la conclusión de la incorporeidad del pensamiento en el tiempo teórico de la negación de todo lo probable, implicaria que la certeza critica de las cosas corporales requiriese todavía de una mediación argumentativa a partir de su ser pensado. La preeminencia ónticamente intuitiva de la autoconciencia pensante parece implicar la "quaestio de ponte", pero esto seria así porque la Ontología de la autoconciencia cartesiana no hace del ser inmaterial el fundamento de la asimilación al todo de lo real, sino que se interpreta por analogia a las cosas fisicas. Según Canals, tal seria el presupuesto que generaria el "idealismo empirico": "En este modo de ver la naturaleza del sujeto cognoscente se aplican paradojicamente al mismo las determinaciones entitativas caracteristicas de los entes naturales que aparecen a la sensibilidad" (Ibid). Podriamos precisar que este "naturalismo" implicaria el conocimiento de si mismo en cuanto "sujeto" del que no tenemos conocimiento inmediato sino en cuanto "supuesto" de sus accidentes: "certum est cogitationem non posse esse sine re cogitante, nec omnimo ullum actum, sive "thum accidens, sine substantia cui insit. Cum autem ipsam substantiam non inmediate per ipsam cognoscamus, sed per hoc tantum quod sit subjectum quorundam actuum" (III Res. AT-VII-175).

\section{La escisión de la idea}

Hasta aqui Canals no parece sino moverse en la linea heideggeriana de Ser y tiempo. Pero en su posterior obra Sobre la esencia del conocimiento retoma la cuestión precisamente acentuando el desenfocamiento de Heidegger en su Discusion hermenéutica de la ontologia cartesiana 
del mundo. Para Heidegger, el fundamento ontológico de la determinación del "mundo" como extensión consiste en que la certeza matemática cumple con la esencia ejemplar gnoseológica de la intuición "bajo el imperio no quebrantado de la ontologia tradicional", que en Ser y tiempo Heidegger interpreta por el constante "ser ante los ojos". Esta constancia daria la preeminencia a los objetos matemáticos en detrimento de los entes intramundanos, captados según Heidegger por la otra forma de intuición que seria la sensación. Pero, tal como advierte Canals, la intuición según Descartes no se define por el constante "ser ante los ojos" sino por ser "hon dubium conceptunt, qui a sola rationis luce nascitur" (RDI, III, AT-X-369). "sin previa referencia alguna a una realidad distinta de la propia mente pensante" (Sobre la esencia del conocimiento PPU, Barcelona, 1987, p 155) El propio Descartes explicita que las condiciones de la intuición son "simel \& non succesive intelligatur" "propositio clare \& distincte" (RDI, XI, AT$\mathrm{X}$-407). Canals podrá concluir, pues, que "la interpretación heideggeriana de la intuición cartesiana se manjifiesta en su conjunto desorientada. Descartes empuja el intuicionismo en una dirección en la que -en oposición a las doctrinas escolásticas-la noticia intuitiva pierde su referencia a lo existencial y contingente" (SEC, p.143, nota 26). En ese caso, el cogito como modelo de certeza intuitiva no consistiria en su inmediatez entitativa sino en la simultaneidad conceptual de los términos de su proposición. Cabe observar, no obstanté, que la interpretación de Heidegger es coherente con la tendencia de Descartes a interpretar el uso de la intuición a semejanza de la visión "ex ipsa oculorum" (RDI, IX, AT-X-400). La interpretación visual de la esencia del conocimiento verdadero como intuición conceptual es suficientemente sugerente como para comprender que Descartes tienda a interpretar la autopresencia del ser pensante como "idea del alma": "Carn'estant, comme j'ai demonstré, qu'tune chose qui pense, il est impossible que nous puissions jamais penser a aucune chose, que nous n'ayons en mesme temps l'idée de nostre Ame, comme d'une chose capables de penser à tout ce que nous pensons" (A Mersenne, VII, 1641, AT-III-393-394). La equivocidad cartesiana de la noción de idea "pro ommi eo quod immediate a mente percipitur" (III Res. AT-VII-181), pero que también se caracteriza "quod res est objective in intellectu" (MM III, AT-VII-41), anticiparia la confusión entre la autoconciencia existencial y su objetividad inteligible, que conduciria directamente al núcleo de la crítica humeana: el conocimiento del yo personal deberia consistir en la idea de una impresión.

\section{La escisión de la esencia}

Con todo, Canals se centra en el hecho de que la fase sintética resolutiva del "cogito" revela la novedad del concepto cartesiano de la intuición que determinará el encubrimiento originario del ser del "cogito", no por la línea del intuicionismo entitativo naturalista o eidético psicologista sino esencial-logicista. En las Meditaciones metafisicas la ejemplaridad criteriológica del "cogito" se toma en cuanto "sum certus me esse rem cogitantem" y se aplica "ut de aliqua re sim certus", para esto no se requiera otra cosa que "clara quaedam \& distincta perceptio ejus affrmo" (MM III, AT-VII-35). En el Discurso del mélodo se determina en orden a la certeza de una "proposition", de tal modo que lo así considerado como primera verdad es el "pienso, luego existo", en lo cual no hay otra cosa que asegure la verdad "sinon que je vois très clairement que, pour penser, il faut être" (DM, IV, AT-VI-33). Y en los Principios de filosofia la solidez del cogito se mantiene en que "repugnat enim, ut putemus id quod cogitat, eo ipso tempore quod cogitat, non existere" (PPh, I, 7, AT-VIII-A-7). Mientras que en otros pasajes Descartes reconoce que de los preconocimientos inmediatos requeridos en el cogito se está suficientemente persuadido por "propria experientia, eaque conscientia, vel interno testimonio, quod in 
se ipso umusquisque, cum res perpendit, experinur" (RV, AT-X-524), en los Principios de Filosofia se consideran como "simplicissimae notiones, \& quae solae mullius rei existentis notitiam praebent" (PPh, I, 10, AT-VIIl-A-3). La exégesis de Canals se orienta a partir de la serie de ejemplos de intuición definida en las "Regulae" en que Descartes asimila la autoconciencia pensante y de sí como existente con verdades de razón matemáticas: "Ila umisquisque animo potest intueri se existere, se cogitare, triangulum terminari triebus lineis tantum, globum unica superficic" (RDE, III, AT-X-368). "La inmediatez imima de la conciencia existencial del sujeto existemte y operante es puesta como si perteneciese a la linea objetiva de algo no dudosamente concebido" (SEC, p.155). "En la formulación cartesiana no se patentiza la certeza indubitable de mi existencia percibida al ser y'o consciente en acto" (SEC, pág. 347) "puesta en el mismo plano que las evidencias de la colterencia necesaria de las esencias" (lbid). Este "esencialismo" del cogito es el que conduciria a buscar la "seguridad" de su juicio existencial en una relación analítica tal como que "para pensar hay que ser". Asi el cogito será blanco de la crítica kantiana, que le atribuiria "a Descartes algo asi como una prueba ontológica en que no se atribuye por necesidad esencial la existencia al ente de perfección infinita, sino precisamente a la naturaleza pensante, al alma o yo humano" (SEC, pág. 347). El intuicionismo esencialista conducirá a imponer como "carácter propiamente cartesiano" del cogito, no la inmediatez intima de la autoconciencia existencial en cuanto pensante, sino del pensamiento de sí como el ser necesario Podriamos precisar, como la del ser pensado en cuanto inmediato indeterminado de que parte la Lógica de Hegel. 